\title{
Photoelectrochemical Oxidation of DNA by Ruthenium Tris(bipyridine) on a Tin Oxide Nanoparticle Electrode
}

\author{
Minmin Liang, Shili Liu, Mingyuan Wei, and Liang-Hong Guo* \\ State Key Laboratory of Environmental Chemistry and Ecotoxicology, Research Center for Eco-environmental Sciences, \\ Chinese Academy of Sciences, P.O. Box 2871, Beijing 100085, China
}

Selective photoelectrochemical oxidation of DNA was achieved by ruthenium tris(bipyridine) immobilized on a tin oxide nanoparticle electrode. The metal complex was covalently attached to a protein, avidin, which adsorbed strongly on the tin oxide electrode by electrostatic interaction. Upon irradiation with 473-nm light, anodic photocurrent was generated in a blank electrolyte and was enhanced significantly after addition of poly(guanadylic acid) (poly-G) into the electrolyte. The current increased progressively with the nucleotide concentration, suggesting the enhancement effect was related to poly-G. The action spectrum indicates that the photocurrent was initiated by light absorption of the ruthenium compound immobilized on the electrode. Among the various polynucleotides examined, poly-G produced the largest photocurrent increase, followed by poly- $A$, single-stranded DNA, chemically damaged DNA, and double-stranded DNA, whereas poly-C and poly- $U$ showed little effect. The combined experimental data support the hypothesis that the photoexcited $\mathbf{R u}^{2+*}$ species injects an electron into the semiconductor and produces $\mathrm{Ru}^{3+}$, which is then reduced back to $R u^{2+}$ by guanine and adenine bases in DNA, resulting in the recycling of the metal complex and enhanced photocurrent. The photoelectrochemical reaction can be employed as a new method for the detection of DNA damage.

Oxidation of DNA bases has been studied extensively in the last two decades due to the important role of DNA in aging and metabolism. ${ }^{1-4}$ Electrochemistry provides a simple but powerful technique for obtaining both kinetic and thermodynamic information on DNA oxidation reactions. Using metal polypyridine complexes as electron mediators, electrocatalytic oxidation of DNA bases was investigated in detail. 5,6 The same strategy was also

* Corresponding author. Telephone: (86)-10-62849685. Fax: (86)-10-62849685. E-mail: LHGuo@mail.rcees.ac.cn.

(1) Steenken, S. Chem. Rev. 1989, 89, 503

(2) Armitage, B. Chem. Rev. 1998, 98, 1171.

(3) Erkkila, K. E.; Odom, D. T.; Barton, J. K. Chem. Rev. 1999, 99, 2777.

(4) Schuster, G. B. Acc. Chem. Res. 2000, 33, 253.

(5) Thorp, H. H. TIBTECH 1998, 16, 117.

10.1021/ac051926y CCC: $\$ 33.50$ C 2006 American Chemical Society Published on Web 12/08/2005 employed in the detection of DNA oxidative damage. ${ }^{7}$ In addition, electrochemiluminescence was used to detect DNA damage on films containing metal polypyridine complexes. ${ }^{8,9}$ We report here the first observation of DNA oxidation catalyzed photoelectrochemically by ruthenium tris(bipyridine) immobilized on a tin oxide nanoparticle electrode.

Photoelectrochemistry has been utilized extensively in the construction of solar cells. In one of the most successful photoelectrochemical solar cells developed by O'Regan and Gratzel, ${ }^{10} \mathrm{a}$ thick, porous film of nanocrystalline $\mathrm{TiO}_{2}$ particles was sensitized by surface-adsorbed ruthenium polypyridyl complex. Other wide bandgap semiconductors and sensitizers have also been investigated. ${ }^{11-13}$ In a few reports, the technique was also employed in chemical and biological analysis, using organic, metal chelate and nanoparticle photoelectrochemical indicators and conducting electrodes. ${ }^{14-19}$ Recently, we reported the first case of quantitative detection of a biological affinity reaction, ${ }^{20}$ using a ruthenium polypyridine complex as a photoelectrochemical label, oxalate as the sacrificial electron donor, and nanoparticle $\mathrm{SnO}_{2}$ as electrode material. The analytical system possesses many attributes of the high quantum yield solar cell, such as high electrode surface area, optimal match of energy level between label and $\mathrm{SnO}_{2}$ conduction band edge, fast charge separation on a semiconductor electrode, and recycling

(6) Thorp, H. H. Top. Curr. Chem. 2004, 237, 159.

(7) Rusling, J. F. Biosens. Bioelectron. 2004, 20, 1022.

(8) Dennany, L.; Forster, R. J.; Rusling, J. F. J. Am. Chem. Soc. 2003, 125, 5213.

(9) Dennany, L.; Forster, R. J.; White, B.; Smyth, M.; Rusling, J. F. J. Am. Chem. Soc. 2004, 126, 8835.

(10) O’Regan, B.; Gratzel, M. Nature 1991, 353, 737.

(11) Kalyanasundaram, K.; Gratzel, M. Coord. Chem. Rev. 1998, 77, 347.

(12) Kelly, C. A.; Meyer, G. J. Coord. Chem. Rev. 2001, 211, 295.

(13) Kamat, P. V.; Bedja, I.; Hotchandani, S.; Patterson, L. K. J. Phys. Chem. 1996, 100, 4900.

(14) Weber, S. G.; Morgan, D. M.; Elbicki, J. M. Clin. Chem. 1983, 29, 1665

(15) Pandey, P. C.; Weetall, H. H. Anal. Chem. 1994, 66, 1236.

(16) Nakamura, S.; Shibata, A.; Takenaka, S.; Takagi, M. Anal. Sci. 2001, 17, i431.

(17) Okamoto, A.; Kamei, T.; Tanaka, K.; Saito, I. J. Am. Chem. Soc. 2004, 126, 14732.

(18) Willner, I.; Patolsky, F.; Wasserman, J. Angew. Chem., Int. Ed. 2001, 40, 1861.

(19) Gao, Z.; Tansil, N. C. Nucleic Acids Res. 2005, 33, e123.

(20) Dong, D.; Zheng, D.; Wang, F.-Q.; Yang, X.-Q.; Wang, N.; Li, Y.-G.; Guo, L.-H.; Cheng, J. Anal. Chem. 2004, 72, 499. 
of the label. Due to its separate source for excitation and detection, a photoelectrochemistry-based analytical method is potentially very sensitive. An additional benefit in comparison with all optical detection methods is the low cost inherent to electronic detection, which becomes a significant issue in array-based analysis.

In the system of our previous work, the ruthenium complex absorbs photon energy and becomes electronically excited. Injection of the excited electrons into the conduction band of the $\mathrm{SnO}_{2}$ electrode produces the $\mathrm{Ru}^{3+}$ species. The sacrificial electron donor oxalate reduces $\mathrm{Ru}^{3+}$ back to $\mathrm{Ru}^{2+}$ and sustains the photocurrent. Since electrochemically generated $\mathrm{Ru}^{3+}$ species has been found to catalyze the oxidation of guanine bases in DNA, 5,6 the same species generated in a photoelectrochemical reaction should be able to oxidize guanine as well. Therefore, if guanine is used instead of oxalate in the photoelectrochemical measurement, photocurrent enhancement would be observed relative to a blank electrolyte. In this paper, we report that photoelectrochemical response of ruthenium tris(bipyridine) immobilized on a nanoparticle $\mathrm{SnO}_{2}$ film electrode was enhanced by polynucleotides dissolved in solution, with the most easily oxidized guanine producing the largest effect. Furthermore, the effect is sensitive to DNA damage, thus providing the basis for detecting DNA damage.

\section{EXPERIMENTAL SECTION}

Ruthenium bis $\left(2,2^{\prime}\right.$-bipyridine) (4-methyl-4'-carboxyl-2,2'-bipyridine) NHS ester (Ru-NHS) was purchased from Fluka; avidin, BCA reagent, styrene oxide, calf thymus (CT) double-stranded (ds) and single-stranded (ss) DNA, poly (guanadylic acid) (5') (poly-G), poly (adenylic acid) (5') (poly-A), poly (uridylic acid) (5') (poly-U), and poly (cytidylic acid) (5') (poly-C) were from Sigma (St. Louis, MO). Poly-G, poly-A, poly-C, poly-U, and CT ds-DNA were dissolved in buffer (20 mM sodium phosphate, $50 \mathrm{mM} \mathrm{NaCl}$, $\mathrm{pH}$ 7.3) and quantitated by absorbance at $260 \mathrm{~nm}$. Fifteen percent tin(IV) oxide, as a colloidal dispersion of 15-nm particles in water, was obtained from Alfa Aesar (Ward Hill, MA). All other chemicals and solvents were analytical grade reagents. Solutions were prepared in high-purity water from a Millipore Milli-Q (Biocel) water purification system. Indium-tin oxide (ITO) conductive glass was supplied by Weiguang Corp. (Shenzhen, P. R. China).

Avidin was labeled with $\mathrm{Ru}-\mathrm{NHS}$ by the following procedure. The $\mathrm{Ru}-\mathrm{NHS}$ was dissolved in dry dimethylformamide and then transferred to an avidin solution in $20 \mathrm{mM}$ sodium phosphate buffer, pH 7.5 (Ru/avidin ratio 15:1). After $1 \mathrm{~h}$ mixing in the dark, unreacted $\mathrm{Ru}-\mathrm{NHS}$ was separated from the protein by gel filtration using a Bio-Rad 10DG column. The ruthenium content on avidin was determined by UV-visible spectroscopy. Protein concentration was determined using the BCA reagent. The ratio of $\mathrm{Ru}$ /avidin was found to be $3.8: 1$.

ITO-coated glass (coating $96 \pm 4 \mathrm{~nm}$, sheet resistance $18 \pm$ $2 \Omega$ /square,) was cleaned in an ultrasonic cleaner sequentially with each of the following solutions: household detergent in water (15 $\mathrm{min}$ ), deionized water ( $2 \mathrm{~min}$, twice), acetone (5 min), 2-propanol (5 min), and deionized water (10 min, twice). Fifteen percent tin(IV) oxide, as a colloidal dispersion of 15-nm particles in water, was spread on a piece of ITO-coated glass and was dried in air on a warm plate. The film was then sintered at $450{ }^{\circ} \mathrm{C}$ for $30 \mathrm{~min}$. The semiconductor thin films at $450{ }^{\circ} \mathrm{C}$ adhered strongly to the glass surface. The $\mathrm{SnO}_{2}$ electrodes were coated with

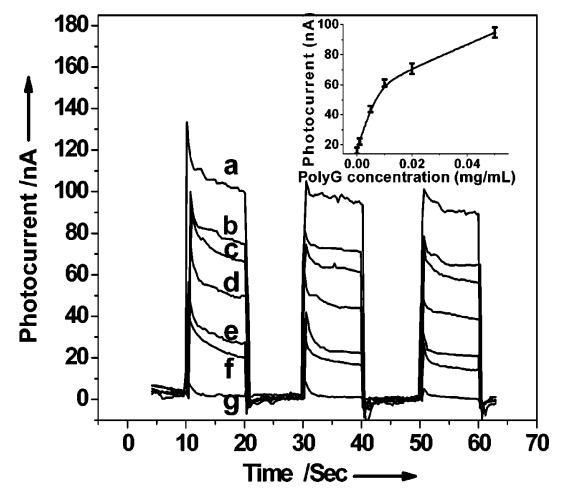

Figure 1. Anodic photocurrent response of avidin-Ru-coated $\mathrm{SnO}_{2}$ nanoparticle electrode in the presence of poly-G, (a) 50, (b) 20, (c) 10, (d) 5 , (e) 1 , and (f) $0 \mu \mathrm{g} / \mathrm{mL}$ and (g) avidin. Inset: Plot of photocurrent measured at 40th second against poly-G concentration. Photocurrent measurement was performed in $20 \mathrm{mM}$ phosphate buffer, pH 5.5. The light source was a 473-nm, 20-mW laser and was turned on and off every $10 \mathrm{~s}$.

$\mathrm{Ru}$-NHS-labeled avidin by incubating in $0.1 \mathrm{mg} / \mathrm{mL}$ avidin- $\mathrm{Ru}$ solution (in $20 \mathrm{mM}$ phosphate buffer) for $1 \mathrm{~h}^{21}$ The resulting electrodes were rinsed with water for $5 \mathrm{~min}$.

DNA was incubated with known DNA damage agent styrene oxide by the following procedure. ${ }^{8} \mathrm{CT}$ ds-DNA was dissolved at

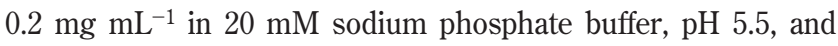
then stirred with $2 \%$ styrene oxide for $30 \mathrm{~min}$ at $37^{\circ} \mathrm{C}$ in a closed vessel. Styrene oxide was then extracted with ether.

\section{RESULTS AND DISCUSSION}

When the avidin-Ru modified electrode was placed in an electrolyte (20 mM sodium phosphate, $\mathrm{pH}$ 5.5) and irradiated with 473-nm light, some anodic photocurrent was obtained, as illustrated in Figure 1a. This background photocurrent was caused mostly by the Ru label, as the avidin-coated electrode (no label) produced much lower current (Figure $1 \mathrm{~g}$ ). After addition of as little as $1 \mu \mathrm{g} / \mathrm{mL}$ poly-G into the electrolyte, the photocurrent increased significantly. The current was relatively stable over time and could be turned on and off by controlling the light. As more poly-G was added, the current initially increased very rapidly and then leveled off. With the highest concentration of poly-G investigated $(50 \mu \mathrm{g} / \mathrm{mL})$, the photocurrent is five times as much as the electrolyte. So poly-G worked as an efficient photocurrent enhancer.

Figure 2 displays the photocurrent in $40 \mu \mathrm{g} / \mathrm{mL}$ poly- $\mathrm{G}$ as a function of excitation wavelength. The action spectrum looks similar to the absorption band of Ru-labeled avidin solution, with a maximum at $470 \mathrm{~nm}$. The similarity suggests the photocurrent originates from the photoexcitation of the metal complex. The bare electrode did not show such a peak.

Other polynucleotides were also investigated as possible electron donors for the oxidized ruthenium complex, which include poly-A, ploy-C, ploy-U, ds-DNA, ss-DNA, and DNA treated with styrene oxide to induce chemical damage. To make a fair comparison, all the polynucleotide solutions had the same concentration of total nucleotides $(50 \mu \mathrm{g} / \mathrm{mL})$, regardless of the polymer length. Quartz crystal microbalance measurements indicate the nucleotides did not adsorb appreciably on the avidin-

(21) Guo, L.-H.; Yang, X.-Q. Analyst 2005, 130, 1027. 




Figure 2. Anodic photocurrent response as a function of excitation wavelength measured in $40 \mu \mathrm{g} / \mathrm{mL}$ poly-G, pH 5.5 , and with a $500-\mathrm{W}$ xenon lamp as the light source. Electrodes are bare $\mathrm{SnO}_{2}(\bullet)$, and

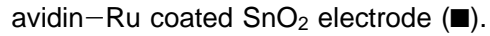

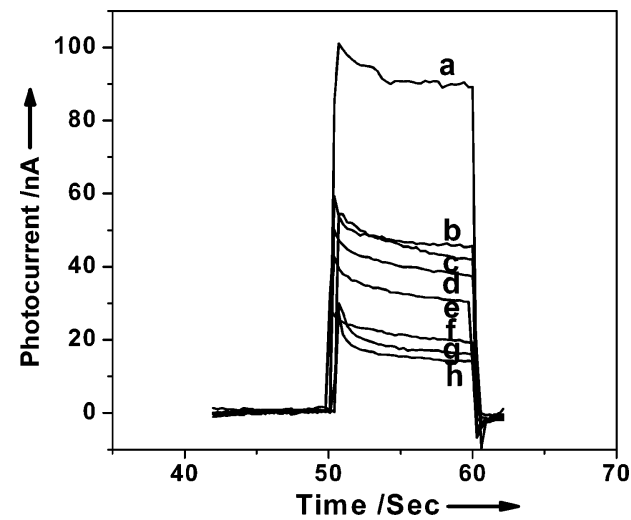

Figure 3. Anodic photocurrent response of avidin-Ru-coated $\mathrm{SnO}_{2}$ nanoparticle electrode in the presence of $50 \mu \mathrm{g} / \mathrm{mL}$ nucleotides: (a) poly-G, (b) poly-A, (c) ss-DNA, (d) damaged DNA, (e) ds-DNA, (f) poly- $\mathrm{C}$, and $(\mathrm{g})$ poly- $U$ and $(\mathrm{h})$ without nucleotide. Photocurrent measurement was performed in $20 \mathrm{mM}$ phosphate buffer, $\mathrm{pH} 5.5$. The light source was a 473-nm, 20-mW laser.

coated surface. The nucleotides were also found to be photostable in the experimental time frame. Figure 3 shows that the photocurrent enhanced by poly-A is about half of poly-G, whereas poly-C and poly-U did not show much effect. Among the four bases, guanine is the most easily oxidized (oxidation potential $\sim 1.0 \mathrm{~V}$ ), followed by adenine $(\sim 1.2 \mathrm{~V})$, while cytosine and uracil have even higher oxidation potentials. ${ }^{22} \mathrm{The} \mathrm{Ru}^{3+/ 2+}$ species $(\sim 1.1 \mathrm{~V})$ should be able to oxidize guanine easily, and adenine to some extent, but not the other two. So the observed order of photocurrent magnitude makes thermodynamic sense.

Enhanced photocurrent was also observed in double-stranded DNA, but the increase is only one-quarter of poly-G. The lower efficiency is not only related to the lesser number of guanine bases

(22) Fojta, M. Electroanalysis 2002, 14, 1449.

(23) Johnston, D. H.; Glasgow, K. C.; Thorp, H. H. J. Am. Chem. Soc. 1995 117, 8933.

(24) Mugweru, A.; Rusling, J. F. Anal. Chem. 2002, 74, 4044.
Scheme 1. Proposed Mechanisms of Photoelectrochemical Oxidation of DNA by $\mathbf{R u}(\mathbf{b p y})_{3}{ }^{2+}$

$$
\begin{array}{lll}
\mathrm{Ru}^{2+}+\mathrm{hv} & \longrightarrow & \mathrm{Ru}^{2+*} \\
\mathrm{Ru}^{2+*}+\mathrm{SnO}_{2} & \longrightarrow & \mathrm{Ru}^{3+}+\mathrm{SnO}_{2}(\mathrm{e}) \\
\mathrm{Ru}^{3+}+\mathrm{G}(\text { or } \mathrm{A}) & \longrightarrow & \mathrm{Ru}^{2+}+\mathrm{G}_{\mathrm{ox}}\left(\text { or } \mathrm{A}_{\text {ox }}\right)
\end{array}
$$

in DNA, but might also be caused by the hindered access of the bases in the helical structure. ${ }^{23}$ The open structure of singlestranded DNA provides better access to the bases, resulting in higher photocurrent. The situation is similar with chemically damaged DNA. After treatment of DNA with styrene oxide, some of the bases are chemically oxidized, causing partial disruption of the double-helix structure. As a result, some of the unreacted bases are now more accessible. ${ }^{24}$ The increase of the photocurrent response in damaged DNA compared with untreated DNA is small but significant. Furthermore, the current increased with the concentration of the damaged DNA, thus providing the basis for quantitative detection of DNA damage.

Photocurrent enhancement requires regeneration of the groundstate $\mathrm{Ru}^{2+}$ complex by a reducing agent. By analogy with previously proposed mechanisms for electrocatalytic oxidation of DNA, 5,6 the photoelectrochemical oxidation reaction in the current system could be represented as in Scheme 1.

Initial excitation of $\mathrm{Ru}^{2+}$ after absorbing photon energy gives $\mathrm{Ru}^{2+*}$ (eq 1). $\mathrm{Ru}^{2+*}$ injects an electron into the semiconductor and produces $\mathrm{Ru}^{3+}$ (eq 2), which is then reduced back to $\mathrm{Ru}^{2+}$ (eq 3) by guanine and adenine bases in DNA, resulting in the recycling of the metal complex and enhanced photocurrent. Because the oxidation potential of $\mathrm{Ru}^{2+* / 1+}(0.78 \mathrm{~V})$ is much lower than that of guanine and adenine, ${ }^{14}$ the excited state does not oxidize the DNA bases directly.

\section{CONCLUSIONS}

Photoelectrochemical oxidation of DNA by ruthenium tris(bipyridine) immobilized on a tin oxide nanoparticle electrode was achieved for the first time. Upon light excitation, photocurrent enhancement was observed in nucleotide solutions, which acted as the electron donor for $\mathrm{Ru}^{3+}$ generated from interfacial electron injection of photoexcited $\mathrm{Ru}^{2+*}$. The enhancement efficiency depended on the type of the base in the nucleotide, as well as DNA structure. Therefore, the photoelectrochemical reaction can be employed as a new method for the detection of DNA damage.

\section{ACKNOWLEDGMENT}

This work was supported by a start-up fund provided by the Chinese Academy of Sciences.

Received for review October 27, 2005. Accepted November 9, 2005.

AC051926Y 